\title{
Complete Blood Count (CBC): Automated versus Manual Differential
}

\section{Henry J Simon and Michael W Simon* \\ Department of Pediatrics, University of Kentucky, USA}

We have evolved into an automated high tech practice of medicine. With speed and automated precision we have sacrificed diagnostic information. The automated differential reports out groups of white blood cell types. With a manual differential, those groups are more specifically differentiated including immature neutrophils (bands) and atypical lymphocytes which are not routinely reported with an automated differential. When an automated differential is done, there may be certain triggers that would necessitate a manual differential be done [1,2]. However these triggers may be certain extreme values reported on the automated differential.

We have traditionally used the band count to help predict a bacterial infection with a "left shift". The atypical lymphocytes are seen with a number of different medical conditions including infections, drug and toxic reactions, post-perfusion syndrome, radiation exposure, autoimmune disorders, malignant disease, hormonal causes and idiopathic disorders like myasthenia gravis, Guillain-barre syndrome, lupus, rheumatoid arthritis and sarcoidosis [3]. Further, certain types of infectious agents will produce characteristic differential findings. For example an atypical lymphocytes count greater than $10 \%$ may be seen with Epstein-Barr virus infections. A few eosinophils noted along with a few atypical lymphocytes may occur with Mycoplasma infections. A manual differential showing 5 to 8 atypical lymphocytes may be seen with adenovirus infections. When an automated differential is performed we lose this diagnostic information which is not only helpful but also may be critical in more precisely diagnosing and effectively treating an ill patient.

\section{References}

1. Hongbo Y, Young C, Hesse A, et al. (2012) Evaluation of an automated digital imaging system, nextslide digital review network, for examination of peripheral blood smears. Arch Pathol Lab Med 136: 660-667.

2. Meintker L, Ringwald J, Rauh M, et al. (2013) Comparison of automated differential blood cell counts from abbott sapphire, siemens advia 120 , beckman coulter $\mathrm{dxh} 800$, and sysmex xe2100 in normal and pathologic samples. AM J Clin Pathol 139: 641-650.

3. Simon MW (2003) The Atypical Lymphocyte. Int Pediatr 18: 2022.
*Corresponding author: Michael W Simon, Department of Pediatrics, University of Kentucky, 610 East Brannon Road, Nicholasville, Ky, USA

Accepted: June 15, 2019

Published online: June 17, 2019

Citation: Simon HJ, Simon MW (2019) Complete Blood Count (CBC): Automated versus Manual Differential. Clin Pediatr Res $3(1): 55$

Copyright: (C) 2019 Simon HJ, et al. This is an open-access article distributed under the terms of the Creative Commons Attribution License, which permits unrestricted use, distribution, and reproduction in any medium, provided the original author and source are credited. 